STRUCTURAL SCIENCE CRYSTAL ENGINEERING MATERIALS

ISSN 2052-5206

Keywords: book review; minerals; mineralogy

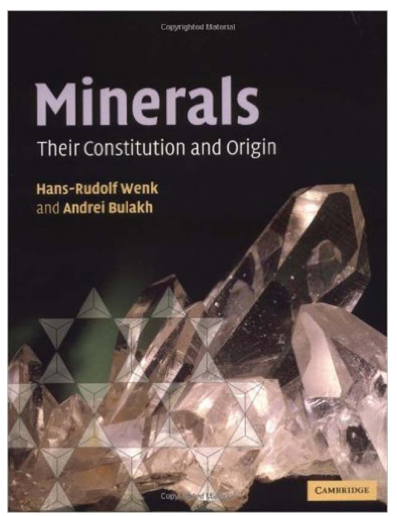

(C) 2017 International Union of Crystallography

\section{Minerals. Their Constitution and Origin. 2nd edition. By Hans-Rudolf Wenk and Andrey Bulakh. Cambridge University Press, 2016. Pp. 672. Price GBP 44.99 (ISBN 9781107514041, paperback), GBP 99.99 (ISBN $\mathbf{9 7 8 1 1 0 7 1 0 6 2 6 0}$ hardcover)}

\author{
Ekkehart Tillmanns*
}

Institut für Mineralogie und Kristallographie, Universität Wien, Geozentrum, Althanstrasse 14, 1090 Wien, Austria. *Correspondence e-mail: ekkehart.tillmanns@univie.ac.at

In six parts with a total of 38 chapters on 672 pages this book covers nearly all aspects of mineralogy in as much detail as is probably needed for undergraduate and graduate students. With its broad list of references and many links to relevant webpages it will also be useful for those who teach classes about these topics. The webpage links were of course not included in the first edition which appeared in 2004; other important additions are an overview of the shift in mineral production during the last 12 years and a number of digital materials that might be useful for instructors: PowerPoint files from which teachers can select slides, and sample laboratory exercises based on a one-semester Berkeley mineralogy course. A Kindle edition is also available.

Part one deals with 'Minerals as chemical compounds' with an overview on history, elements and bonding, chemical formulae and chemical classification.

Part two 'Symmetry expressed in crystal structures and morphology' contains the basic concepts of lattices, point- and space-groups, defects and crystal growth. As in many other older textbooks the definition of the lattice constants in the different crystal systems is not exact: in the triclinic system for example $a, b, c, \alpha, \beta, \gamma$ are not principally unequal but just not restricted. The crystal system depends on the symmetry and the lattice geometry is a consequence of the symmetry and not vice versa.

Part three 'Physical investigations and properties of minerals' gives an overview of Xray diffraction, physical, optical and mechanical properties, the use of the petrographic microscope, color of minerals and advanced analytical methods.

Part four 'Mineral-forming processes' deals with mineral genesis, basic concepts of thermodynamics and phase diagrams.

Part five 'A systematic look at mineral groups' follows generally the Strunz-Nickel classification with the exception that the most common minerals in the continental crust, quartz and feldspar are dealt with first in order to better understand rock-forming processes and mineral parageneses. I was surprised that beryl and cordierite are still classified as ring silicates, following Machatschki-Bragg while the modern topological classification of Zoltai considers them as framework silicates since the six-rings are further connected via common corners to the Al- or Be-tetrahedra. But this may be a question of definition.

Part six 'Applied mineralogy' contains information about metalliferous deposits, gemstones, cement minerals, an important chapter about minerals and human health, and the composition of the earth and the solar system.

The text is well written, figures are generally clear and instructive, a total of 188 color photographs of hand specimen, thin sections with plane and crossed polarizers, and optical interference figures of uniaxial and biaxial crystals are a very useful addition. The price of $£ 44.99$ for the paperback edition and $£ 99.99$ for hardcover is very reasonable in comparison to other textbooks in this field.

To summarize: the book can be recommended without restriction. 